\title{
Dampak CR, DER dan NPM terhadap Tobin`s Perusahaan Sub Sektor Kosmetik dan Barang Keperluan Rumah Tangga yang terdaftar di BEI
}

\author{
Debi Eka Putri \\ Sekolah Tinggi Ilmu Ekonomi Sultan Agung \\ debiekaputri@stiesultanagung.ac.id \\ Eka Purnama Sari \\ Universitas Potensi Utama \\ sariekapurnama42@gmail.com
}

\begin{abstract}
Abstrak The purpose oft his study is to look at and analyze the effect of CR, DER, NPM on Tobin's $Q$ together and individually in theCosmetics and Household Utilization Sub-sector Companies Listed on the IDX. The approach used is an associative approach. This type of data uses quantitative data. All Cosmetics and Household Goods Sub-sector companies registered on the IDX are used for this population while the sample that meets the criteria with purposive sampling techniqueis 4 companies for 8 years of research. Data collection techniques using documentation. Techniques for analyzing data use multiple linear regression, correlation, $R$-Square also hypothesis testing. The results prove simultaneously that $C R, D E R, N P M$ have a significant effect on Tobin's $Q$. Partially $C R$ has an insignificant positive effect on Tobin's $Q$, while DER and NPM have a significant positive effect on Tobin's $Q$.
\end{abstract}

Kata Kunci $\quad C R, D E R, N P M$, Tobin's $Q$

\section{PENDAHULUAN}

Era perkembangan baru manajemen perusahaan semakin bergeser ke arahstrategiberbasis pemangku kepentingan dengan lebih memperhatikan minatpemangkukepentingan dalam mencapai tujuan perusahaan (Siahaan, Susantidan Sudirman,2020).Calon investor maupun seorang investor melihat eksistensi suatu perusahaan di pasar modal tidak hanya fokus pada pencapaian laba yang tinggi sebagai tolak ukur kinerja, tetapi melihat nilai perusahaan yang terdapat di perusahaan terkait. Nilai perusahaan kerap dihubungkan dengan harga saham yakni sebagai tanggapan investor kepada tingkat keberhasilan perusahaan. Tingginya pertumbuhan nilai perusahaan membentuksuatu keinginanuntuk para yang memiliki perusahaan, hal ini menunjukkan kesejahteraan investor. Seorang Professor berkebangsaan Amerika Serikat, James Tobin menemukan suatu metode yang dikenal dengan istilah Tobin's Q untukmemperkirakannilai perusahaan. Model ini diukur melalui nilai pasar ekuitas dengan biaya ganti aktivanya. Nilai pasar modaldidapat melaluijumlah perkalian antara harga saham penutupan dan jumlah saham beredar. Apabila nilai Tobin's Qlebih dari dari satu,pertumbuhan investasi tinggi dan begitu pula sebaliknya.

Perusahaantentunya memiliki hutang dan perlu melihat kemampuan dalam melunasi hutang-hutangnya yang ada saat ini dengan asset yang dimilikinya. Rasio likuiditas yang menggambarkan tentang kapabilitas perusahaan untukmenutupi utang lancermelalui memanfaatkan aset tidak tetapmilik perusahaandisebut sebagai Current Ratio (CR). Semakin tinggi persentase $\mathrm{CR}$, kondisi menunjukkan likuidnya suatu instansi, memberikan 
asumsibaikpadakedudukaninstansi. Hasil penelitian terdahulu (Rompas, 2013b)menyimpulkan bahwa Current Ratio(CR)memiliki pengaruh terhadap Tobin's Q, berbeda dengan penelitian (Chairunnisa, 2019)menunjukkan bahwa $C R$ tidak memiliki pengaruh signifikan terhadap Tobin's Q.

Umumnyainstansi menggunakan pinjaman berupa hutang dalam pembiayaan kegiatan operasional perusahaan tersebut. Para kreditor menyalurkan pinjaman dana dan mendapat informasi keuangan untuk memantau kapabilitasinstansiuntuk melunasi utang. DERdipakai untuk mengukurtotal utangdan total ekuitas, Semakin besar nilaiDERmaka instansisemakin tidak baik finansialnya dan resiko perusahaan juga semakin tinggi. Ini dapat dikarenakan besarnya penggunaan utang. Dan hal inimencerminkan semakin tinggi risiko instansiuntuk melunasiutangnya(Halim, 2007). Hasil penelitian (Chasanah, 2018)menyimpulkan bahwa DERtidak memiliki pengaruh signifikan terhadap Tobin's $Q$. Beda dengan (Kurnianto and Asakdiyah, 2016)yang menyimpulkan DERmemiliki pengaruh yang signifikan terhadap Tobin's $Q$.

Nilai perusahaan bisa diamatimelaluikapabilitas di dalam memperolehprofit. Salah satunya memakaiNPM. NPMdicari dengan melihat perimbanganlaba bersih dengan penjualan yang menghasilkan laba tersebut. Semakin besar nilaiNPM maka semakin apikkualifikasiinstansiyang menyebabkan perolehan penghasilan yang semakin besar pula. Hasil penelitian (Rompas, 2013b)menyatakanNPMberpengaruh terhadap nilai perusahaan.

\section{LANDASAN TEORI}

\subsection{Tobin's $Q$}

Nilai perusahaanbisa memakaiTobin's $Q$. Tobin's Qmelibatkanseluruh utang, modal saham dan semua aktiva yang dimiliki. Dengan adanya aset secara keseluruhan, berarti perusahaan bukansaja fokus ke satu investor padawujud saham tetapidemi kreditur dikarenakananggaran operasional instansi tidak saja dari ekuitas namun dari utangdarikrediturPermanasari dalam(Chairunnisa, 2019).Dalam(Prasetyorini, 2013), Smithers dan Wright mengartikan Tobin's Qmembuktikanperkiraan pasar keuangan sekarangmengenai nilai hasil returndari tiap dolar investasi di waktuyang akan datang.Menurut Sutrisno (2012) aspek yang berdampak ke nilai perusahaan meliputi keputusan (investasi, pendanaan, dan dividen).

\subsection{Current Ratio}

Diantara banyak likuiditas, peneliti hanya memakai yaitu CR. Menurut Sudana (2011), $C R$ mengetahuikapabilitasinstansi dalam membayar utang lancarmelalui caramemanfaatkanasset tidak tetap. Horne dan John (2012), CRmelihatkapabilitas perusahaan dalam memenuhiutang lancarmelalui caramemanfaatkanaktiva lancar. Semakin tinggi rasio ini, akan semakin tinggi kemampuan instansimenutupi tagihannya. Perusahaan yang mempunyaiaktiva lancar sebahagian besar merupakan kas dan piutang yang belum habis masa, pada dasarnya akan dianggap sebagian besar terdiri atas persediaan

\subsection{Debt to Equity Ratio}

$D E R$ salah satu parameter dari rasio leverage. Menurut Kasmir (2012DERberfungsidemimenaksirantara utang dan ekuitas. DERdapat melihat tersedianyadanapada kreditur dengan pemegang perusahaan. Dalam arti lain, dapat melihat tiap rupiah modal pribadi yang dijadikan tanggungan hutang. Syahyunan (2015), DERmengukur perimbangan antar totalutang dengan jumlah dana sendiri 


\subsection{Net Profit Margin}

$N P M$ merupakan satu dari sekian banyak parameter pada rasio profitabilitas. Menurut Fahmi dalam (Putri, Z.A. and N.P., 2016)NPMmencerminkankapabilitas perusahaan untuk memperolehprofit dari tiap penjualan.Hery (2016), menyatakan bahwa marjin laba bersih merupakan perbandingan besarnya laba bersih atas penjualan bersih.

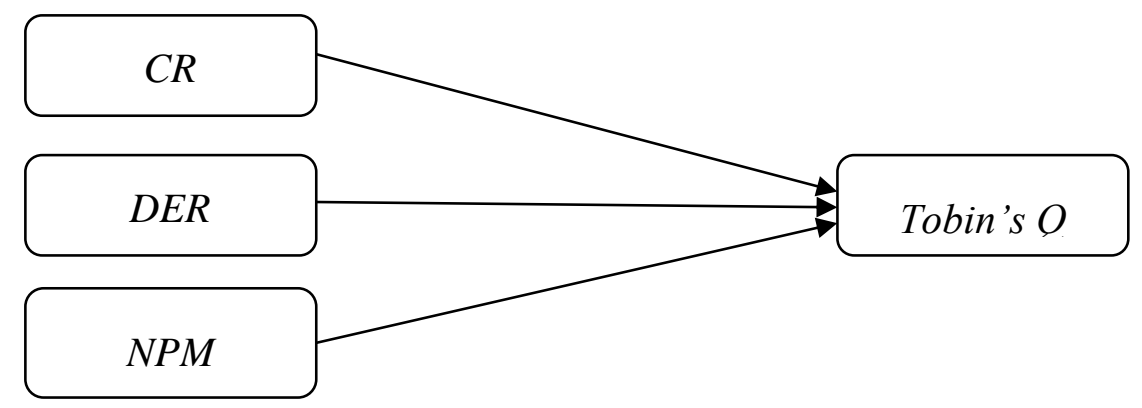

Gambar 1. Model Kerangka Teoritis Penelitian

\section{METODOLOGI PENELITIAN}

Populasi di penelitian iniyaitu perusahaan sub sektor kosmetik dan barang keperluan rumah tangga tahun 2011-2018 berjumlah 6 perusahaan. Sampel yang dipakai yakni purposive sampling yaknipenentuan sampel melalui pertimbangan agar mendapatkan sampelyang berkualifikasi. Kualifikasi atau pertimbangan nan dipakaiyakni perusahaan yang membagikan laporan keuangan denganlengkap tahun penelitian dan yang tidak rugi sepanjang 3 tahun berturut. Maka dari itu hanya4 perusahaan yang dapat dijadikan sampel.Teknik dalam mengumpulan data menggunakan data dokumentasi. Mendokumentasikannyadari laporan keuangan perusahaan sub sektor kosmetik dan barang keperluan rumah tangga yang terlisting di BEItahun 2011-2018. Pengujian dan analisis data yang bersumber dari data primer menggunakan software statistik SPSS versi 21 dengan formulasi regresi linierberganda, koefisien korelasi, $R$-Square serta uji t dan F.

\section{HASIL PENELITIAN}

\subsection{Regresi Linier Berganda}

Tabel 1: Uji Regrei Linear Berganda

\begin{tabular}{|l|r|r|}
\hline \multirow{2}{*}{ Model } & \multicolumn{2}{|c|}{ Unstandardized Coefficients } \\
\cline { 2 - 3 } & \multicolumn{1}{|c|}{ B } & \multicolumn{1}{c|}{ Std. Error } \\
\hline (Constant) & $\mathbf{, 2 7 2}$ &, 325 \\
CR & $\mathbf{, 0 5 4}$ &, 059 \\
DER & $\mathbf{1 , 1 2 7}$ &, 198 \\
NPM & $\mathbf{6 , 8 8 0}$ & 1,283 \\
\hline
\end{tabular}

Sumber: Data Diolah (2020)

Berdasarkan tabel di atas, diperoleh model persamaan regresi, sebagai berikut:

$$
\hat{\mathbf{Y}}=0,272+0,054 X_{1}+1,127 X_{2}+6,880 X_{3}
$$

Persamaan regresi dapat diartikan bahwa CR, DER dan NPMberpengaruh positif terhadap tobin's Q pada sub sektor Kosmetik dan Barang Keperluan Rumah Tangga.

\subsection{Korelasi dan Koefisien Determinasi}


Hasil koefesien determinasi, sebagai berikut:

Tabel 2: Hasil Koefesien Determinasi

\begin{tabular}{|l|l|r|r|r|}
\hline Model & R & R Square & Adjusted R Square & Std. Error of the Estimate \\
\hline 1 &, $921^{\mathrm{a}}$ &, 848 & $\mathbf{8 3 2}$ &, 548273 \\
\hline
\end{tabular}

Sumber: Data Diolah (2020)

Berdasarkantabel 2, nilai $\mathrm{r}$ sebesar 0,921, terdapat korelasi yang sungguh kuat antarCR, DER dan NPMterhadapTobin's Q. kemudiandiperoleh R Squaresebesar 0,848. Hasil menandakanbahwa 84,8 \% variasi dari Tobin's $Q$ diperjelas oleh ketiga variabel dependen (CR, DER, NPM ) dan selebihnya diperjelas oleh faktor yang tidak dibahas seperti risiko bisnis, cash ratio, basic earning power, LTDR, dan sebagainya.

\subsection{Uji Hipotesis}

\subsubsection{Uji Simultan}

Besarnya pengaruh dari seluruh variabel independen secara simultan terhadap variabel dependen digunakan uji F. Hasil uji F, sebagai berikut:

Tabel 3: Hasil Uji F

Sumber: Data Diolah (2020)

\begin{tabular}{|c|c|c|}
\hline Model & $\mathrm{F}$ & Sig. \\
\hline $\begin{array}{ll} & \text { Regression } \\
1 & \text { Residual } \\
& \text { Total }\end{array}$ & 52,058 &, $000^{b}$ \\
\hline
\end{tabular}

Dari tabel 3, nilai $F_{\text {hitung }}$ 52,058 dengan signifikasnsi 0,000. Sedangkan nilai $F_{\text {tabel }} 2,95$, berarti $F_{\text {hitung }}>F_{\text {tabel }}(52,058>2,95)$ menunjukkan $\mathrm{H}_{0}$ ditolak dan $\mathrm{H}_{\mathrm{a}}$ diterima. Jadi bisa dikonklusikanCR, DER dan NPM berpengaruh signifikan terhadap Tobin's Q pada perusahaan Sub Sektor Kosmetik dan Barang Keperluan Rumah Tangga.

\subsubsection{Uji Parsial} berikut:

Untuk mengetahui pengaruh masing-masing variabel digunakan uji t.Hasil uji t, sebagai

Tabel 4: Hasil Uji t

\begin{tabular}{|l|r|r|}
\hline Model & \multicolumn{1}{|c|}{$\mathrm{t}$} & \multicolumn{1}{c|}{ Sig. } \\
\hline Constant) &, 837 &, 410 \\
CR & $\mathbf{, 9 1 8}$ & $\mathbf{, 3 6 6}$ \\
DER & $\mathbf{5 , 5 9 6}$ & $\mathbf{, 0 0 0}$ \\
NPM & $\mathbf{5 , 3 6 4}$ & $\mathbf{, 0 0 0}$ \\
\hline
\end{tabular}

Sumber: Data Diolah (2020) berikut:

Dari tabel 4, dapat dilihat pengaruh tiap variabel $\mathrm{X}$ terhadap variabel $\mathrm{Y}$ yaitu sebagai

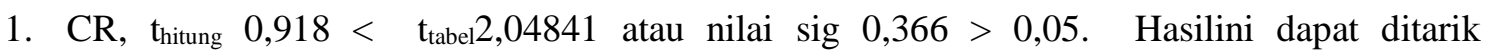
kesimpulan $\mathrm{H}_{0}$ diterima dan $\mathrm{H}_{\mathrm{a}}$ ditolak, yang berartiCRmemiliki pengaruh namun tidak signifikan terhadap tobin's Q pada perusahaan Sub Sektor Kosmetik dan Barang Keperluan Rumah Tangga. 
2. DER, thitung 5,698 $>\mathrm{t}_{\text {tabel }} 2,04841$ atau nilai sig $0,000<0,05$. Ini dapat memiliki kesimpulan $\mathrm{H}_{0}$ ditolak dan $\mathrm{H}_{\mathrm{a}}$ diterima, yang bermaknaDERberpengaruh signifikan terhadap tobin's Q.

3. NPM, nilai $\mathrm{t}_{\text {hitung }} 5,364>\mathrm{t}_{\text {tabel }} 2,04841$ atau nilai sig $0,000<0,05$. Yang bermaknaH $\mathrm{H}_{0}$ ditolak dan $\mathrm{H}_{\mathrm{a}}$ diterima, ini menandakankalau NPMberpengaruh signifikan terhadap tobin's Q.

\section{Pembahasan}

\subsection{Pengaruh Current Ratio Terhadap Tobin's $Q$}

Dari hasil uji diatas, CRberpengaruh positif terhadap Tobin's Q, dengan persamaan:

$$
\hat{\mathbf{Y}}=0,272+0,054 X_{1}+1,127 X_{2}+6,880 X_{3}
$$

Besar pengaruh sebesar 0,054 yang bermaknadikala CRmengalami peningkatansebanyak satu satuan, maka Tobin's Qjuga terjadipenambahan sebesar 0,054 dengan perkiraan dari variabel bebas lainyang diduga tetap.Dari uji t menggambarkanCR berpengaruh tidak signifikan terhadap tobin's Q. Keadaan disebabkan likuiditas tinggi menggambarkan dana berlebihtidak terpakai yang mengakibatkan perusahaan lemah dalam meningkatkan profit sehingga mengakibatkan nilai perusahaan kurang baik di mata calon investor ataupun investor.Hasil penelitian ini tidak sependapat dengan (Rompas, 2013b), (Kombih and Suhardianto, 2017), (Putri, Z.A. and N.P., 2016),menyimpulkan bahwa CRberpengaruh terhadap Tobin's Q. Namun ini juga sependapat dengan penelitian (Chairunnisa, 2019), (Marceline and Harsono, 2017), (Thaib and Dewantoro, 2017), (Nafisah, Halim and Sari, 2018)yang berkesimpulan CRtidak berpengaruh signifikan terhadap Tobin's Q.

\subsection{Pengaruh DER Terhadap Tobin's $Q$}

Dari hasil uji diatas, DERberpengaruh positif terhadap Tobin's Q, dengan persamaan :

$$
\hat{\mathbf{Y}}=0,272+0,054 X_{1}+1,127 X_{2}+6,880 X_{3}
$$

Besarnya pengaruh sebesar1,127 yang bermaknadikalaDERmengalami peningkatan sebanyak satu satuan, Tobin's Q juga meningkat sebesar 1,127 atasdugaan variabel bebas lain diduga tetap. Berdasarkan uji t, DERberpengaruh signifikan terhadap tobin's Q. Beban operasional selalu meningkat menyebabkan perusahaan menggunakan pinjaman. Utang sangat besar akan menambahpeluang perusahaan melawanmasalah pendanaan. Semakin maju perusahaan memungkinkan untuk memakai utang lebih besar. Dalam arti lain, bertambahbesarnyaDERtentu besarjuga tobin's Q. Namun hasil ini tidak sependapat dengan Halim (2007), semakin besarleveragemencerminkan semakin tidak baguskeuangan yang diemban perusahaan. Penyebabnya karenatingginya penggunaan utang. Hal ini berarti semakin tinggileverage dengan aktiva atau leverage dengan ekuitas, menunjukkan semakin tinggi resiko keuangan perusahaan, keadaan tersebutlantaransemakin besarnyarisiko ketidaksanggupaninstansidalam melunasi beban tetap di kondisi perekonomian yang tidak baik.Hasil penelitian sependapat dengan(Kurnianto and Asakdiyah, 2016), (Cahyanto, Darminto and Topowijono, 2014), (Dewi, Handayani and Nuzula, 2014), (Rahmantio, Saifi and Nurlaily, 2018), menyimpulkanDERberpengaruh signifikan terhadap Tobin's Q. Namun hasil diperoleh tidak sependapat dengan(Chasanah, 2018),(Amanah, Rahayu and Sudjana, 2015), (Ogolmagai, 2013), (Kayobi and Anggraeni, 2015),yang menyimpulkan bahwa DERberpengaruh terhadap Tobin's Q.

\subsection{Pengaruh NPM Terhadap Tobin's Q}

Dari uji diatas, NPMberpengaruh positif terhadap Tobin's Q. Dengan persamaan: 


\section{$\hat{Y}=0,272+0,054 X_{1}+1,127 X_{2}+6,880 X_{3}$}

Besar pengaruh yaitu 6,880 yang memiliki artidikalaNPMmengalami peningkatansebanyak satu satuan, Tobin's Qpuntentuterjadipenambahan sebanyak 6,880 dengan dugaan variabel bebas lain didugatetap.Dari uji t mencerminkan NPMberpengaruh signifikan terhadap tobin's Q. Dan inimencerminkanbertambahbesarnyaNPMakan tinggi juga tingkat kemakmuran yang diberikan perusahaan berdasarkan penjualan.Hasil ini sependapat dengan(Rompas, 2013a), (Fintreswari and Sutiono, 2017), menyimpulkan NPM berpengaruh terhadap Tobin's Q.Tetapi hasil ini tidak sependapat dengan (Muliawati dan Muhammad, 2018), dimanaNPM tidak berpengaruh signifikan terhadap Tobin's Q.

\section{KESIMPULAN}

Dari hasil penelitian dan pembahasan diatas, maka bias disimpulkanCR, DER, NPM berpengaruh positif terhadap tobin's Q pada perusahaan Sub Sektor Kosmetik dan Barang Keperluan Rumah Tangga yang Terdaftar di BEI. Kemudian dari hasil uji koefisien korelasi adanyaikatan sangat kuat padaCR, DER, NPM dengan tobin's Q. Selanjutnya uji t, CR, berpengaruh tidak signifikan terhadap tobin's Q. KemudianDERdanNPMberpengaruh signifikan terhadap tobin's Q. Dari kesimpulantercantum, maka peneliti dapat memberikan saran seperti: pihak manajemen diharapkan agar mengoptimalkan asset agar tidak terjadinya penumpukan asset yang berujung kepada banyaknya asset menganggur. Kemudian lebih mengendalikan total hutang setiap tahunnya, karena hutang yang tinggi akan berdampak kepada penurunan laba dan tentunya berimbas kepada harga saham. Untuk meningkatkan nilai perusahaan pihak manajemen juga harap memperhatikan jumlah laba yang diperoleh dari jumlah penjualan yang dimiliki perusahaan. Nilai perusahaan adalah parameter kinerja keuangan untuk instansi secara eksternal, maka dari itu pihak manajemen sebaiknya menjaga trust para investor untuk halpengelolaankeuangan supaya investor tidak merebutkembali dananya. Bagi peneliti yang berkeinginan meneliti judul dan fenomena sama bisa menelitinya pada perusahaan yang berbeda dalam industry yang mungkin tidak berada dalam ruang lingkup sektor yang sejenis, agar menemukan tambahan ilmu pengetahuan dalam hal menganalisis pengaruh CR,DER, dan NPM terhadap tobin's Q dari banyak sektor industri. Untuk the nextpeneliti biasmeneliti dengan cakupan objek penelitian yang luas lagi dan juga menggunakan variabel lain yang mempengaruhi tobin's Q serta memperpanjang periode penelitian sehingga dapat lebih memaksimalkan penelitian yang dilakukan.

\section{DAFTAR PUSTAKA}

Brigham, Eugene F dan Joel F Houston. 2010. Dasar-Dasar Manajemen Keuangan. Edisi Kesebelas. Buku 1. Jakarta: Salemba Empat.

Amanah, R., Rahayu, S. M. and Sudjana, N. (2015) 'PENGARUH STRUKTUR MODAL PERUSAHAAN TERHADAP NILAI PERUSAHAAN (Studi Pada Perusahaan Sub Sektor Tekstil Dan Garmen Yang Terdaftar Di Bursa Efek Indonesia Periode 2009-2013)', Jurnal Administrasi Bisnis S1 Universitas Brawijaya, 22(2), p. 85923.

Cahyanto, S., Darminto and Topowijono (2014) 'PENGARUH STRUKTUR MODAL DAN PROFITABILITAS TERHADAP NILAI PERUSAHAAN (Studi pada Perusahaan Otomotif dan Komponennya yang Terdaftar di Bursa Efek Indonesia Periode Tahun 20102013)', Jurnal Administrasi Bisnis S1 Universitas Brawijaya, 11(1), p. 82464.

Chairunnisa, R. (2019) 'Likuiditas, Aktivitas, dan Profitabilitas Terhadap Nilai Perusahaan Automotive Yang Terdaftar Di BEI', Jurnal Ekonomi Manajemen \& Bisnis, 20(2), pp. 149160.

Chasanah, A. N. (2018) 'Pengaruh Rasio Likuiditas, Profitabilitas, Struktur Modal dan Ukuran 
Perusahaan Terhadap Nilai Perusahaan Pada Perusahaan Manufaktur Yang Terdaftar di BEI Tahun 2015-2017', Jurnal Penelitian Ekonomi dan Bisnis, 3(1), pp. 39-47.

Dewi, I., Handayani, S. R. and Nuzula, N. F. (2014) 'Pengaruh Struktur Modal Terhadap Nilai Perusahaan (Studi Pada Sektor Pertambangan Yang Terdaftar Di Bei Periode 2009-2012)', Jurnal Administrasi Bisnis S1 Universitas Brawijaya, 17(1), p. 85090.

Fintreswari, D. G. and Sutiono, F. (2017) 'Pengaruh Kinerja Keuangan, Good Corporate Governance Terhadap Nilai Perusahaan Food and Beverage', Jurnal Online Insan Akuntan, 2(2), pp. 203-216. doi: 10.9744/jmk.14.2.118-127.

Kayobi, I. G. M. A. and Anggraeni, D. (2015) 'Pengaruh Debt to Equity Ratio (DER), Debt to Total Asset (DTA), Dividen Tunai dan Ukuran Perusahaan Terhadap Nilai Perusahaan (Perusahaan Manufaktur Sektor Barang Konsumsi Yang Terdaftar Di Bursa Efek Indonesia Periode 2011-2014)', Jurnal Akuntansi dan Keuangan, 4(1), pp. 10-17. doi: $10.1145 / 3132847.3132886$.

Kombih, M. T. A. and Suhardianto, N. (2017) 'Pengaruh Aktivitas Pemasaran, Kinerja Keuangan, dan Aset Tidak Berwujud Terhadap Nilai Perusahaan', EKUITAS (Jurnal Ekonomi dan Keuangan), 1(3), p. 281. doi: 10.24034/j25485024.y2017.v1.i3.1909.

Kurnianto, S. and Asakdiyah, S. (2016) 'Analisis Pengaruh Profitabilitas (ROE), Struktur Modal (DER) dan Keputusan Investasi (PER) Terhadap Nilai Perusahaan (Studi Pada Perusahaan Sektor Properti dan Real Estate yang Terdaftar di Bursa Efek Indonesia (BEI) Periode 20112014)', Jurnal Fokus, 6(1), pp. 110-120.

Marceline, L. and Harsono, A. (2017) 'Pengaruh Good Corporate Governance, Karakteristik Perusahaan, likuiditas, Leverage, Kebijakan Deviden, dengan Nilai Perusahaan', Jurnal Bisnis dan Akuntansi, 19(1a), pp. 226-236.

Nafisah, N. I., Halim, A. and Sari, A. R. (2018) 'Pengaruh Return on Assets (Roa), Debt To Equity Ratio(Der), Current Ratio (Cr), Return on Equity (Roe), Price Earning Ratio (Per), Total Assets Turnover (Tato), Dan Earning Per Share (Eps) Terhadap Nilai Perusahaan Manufaktur Yang Terdaftar Di Bei Tahun 2', Jurnal Riset Mahasiswa Akuntansi, 6(2), pp. $1-17$.

Ogolmagai, N. (2013) 'Leverage Pengaruhnya Terhadap Nilai Perusahaan Pada Industri Manufaktur Yang Go Public Di Indonesia', Jurnal EMBA, 1(3), pp. 81-89.

Prasetyorini, B. F. (2013) 'Pengaruh Ukuran Perusahaan, Leverage, Price Earning Ratio dan Profitabilitas Terhadap Nilai Perusahaan', Jurnal Ilmu Manajemen, 1(1), pp. 183-196.

Putri, R. H., Z.A., Z. and N.P., M. G. W. E. (2016) 'Pengaruh Rasio Likuditas dan Rasio PRofitabilitas Terhadap Nilai Perusahaan (Studi Pada Perusahaan Sektor Industri Barang Konsumsi yang Terdaftar di BEI Tahun 2012-2014)', Jurnal Administrasi Bisnis (JAB), 38(2), pp. 38-45.

Rahmantio, I., Saifi, M. and Nurlaily, F. (2018) 'PENGARUH DEBT TO EQUITY RATIO , RETURN ON EQUITY, RETURN ON ASSET DAN UKURAN PERUSAHAAN TERHADAP NILAI PERUSAHAAN ( Studi pada Perusahaan Pertambangan yang Terdaftar di Bursa Efek Indonesia Tahun 2012-2016)', Jurnal Administrasi Bisnis (JAB), 57(1), pp. 151-159.

Rompas, G. P. (2013a) 'Likuiditas, Solvabilitas dan Rentabilitas Terhadap Nilai Perusahaan BUMN Yang Terdaftar Di BEI', Jurnal EMBA, 1(3), pp. 252-262.

Siahaan, Y., Susanti, E., \& Sudirman, A. (2020). Effect of firm characteristics on firm value through triple bottom line disclosure: Pharmaceutical companies listed on Indonesia stock exchange. International Journal of Scientific and Technology Research, 9(2), 2228-2234.

Sudana, I Made. 2011. Manajemen Keuangan Perusahaan: Teori dan Praktik. Jakarta: Erlangga. Sutrisno. 2012. Manajemen Keuangan Teoridan Aplikasi. Yogyakarta: EKONISIA

Syahyunan. 2015. Manajemen Keuangan, Perencanaan, Analisis dan Pengendalian Keuangan. 


\section{JESY^}

JURNAL EKONOMI \& EKONOMI SYARIAH

Jurnal Ekonomi \& Ekonomi Syariah Vol 3 No 2, Juni 2020

E-ISSN : 2599-3410|P-ISSN : 2614-3259

DOI : https://doi.org/10.36778/jesya.v3i2.195

Edisi II. Medan: USU Press

Thaib, I. and Dewantoro, A. (2017) 'Pengaruh Profitabilitas dan likuiditas terhadap nilai perusahaan dengan struktur modal sebagai variabel intervening', Jurnal Riset Perbankan Manajemen Dan Akuntansi, 1(1), pp. 25-44. 